\title{
Pluralidades em Geografia Feminista: uma entrevista com Robyn Longhurst
}

\author{
Rodrigo Rossi \\ GETE - Universidade Estadual de Ponta Grossa - Brasil
}

As geografias feministas e das sexualidades compõem espaços acadêmicos notadamente abertos a pluralidade temática. Este fenômeno tem se evidenciado em muitas trajetórias de pesquisadoras e pesquisadores deste subcampo da geografia humana. Uma das referências na constituição de uma trajetória acadêmica marcada por esta pluralidade é a geógrafa neozelandesa Robyn Longhurst. Sua produção científica nas geografias feministas e das sexualidades tem se constituído em importante contribuição à geografia humana contemporânea no âmbito da relação entre corpo, gênero, espaço e lugar e da crítica à epistemologia e ontologia masculinistas da geografia.

Entrevistamos esta geógrafa feminista que compartilha com as pessoas que editam e leitoras da Revista Latino Americana de Geografia e Gênero concepções, ideias e experiências que estão situadas numa geografia 'lá de baixo' (Geograhies Down Under), pós-estruturalista e fundamentada na teoria Queer. Os estudos de Longhurst se mostram bem variados, envolvem atualmente temáticas como as geografias emocionais e afetivas - espaço, amor, maternidade e tecnologias de informação e comunicação, corpos de mulheres grávidas, obesidade, o cozinhar e os alimentos no contexto de mulheres migrantes.Não obstante, a trajetória de Longhurst também resulta numa importante contribuição aos debates teóricos/epistemológicos sobre o feminismo e a geografia, violência sexual, mulheres grávidas e espaços públicos, corpo, casa, masculinidades, espaços de abjeção e diferença sexual. O caminho percorrido por esta geógrafa revela, além de um conjunto variado de possibilidades de investigação em geografia humana, uma preferência metodológica qualitativa e crítica que contribui para a reflexibilidade na realização de entrevistas em profundidade, semiestruturadas, bem como na realização de grupos focais.

O papel ativo de Robyn Longhurst na Comissão de Gênero da União Geográfica Internacional, também deixaram marcas indeléveis da emergência das geografias feministas e das sexualidades que se orientam a partir do sul.

Nossa entrevista, nesse sentido, tem como objetivo o diálogo sobre os principais eixos da produção acadêmica desta geógrafa, as estratégias das geografias feministas e das sexualidades no contexto transnacional.

$\begin{aligned} & \text { Rodrigo } \\ & \text { Rossi: }\end{aligned}$ Sua trajetória
acadêmica é caracterizada pela
pluralidade de temas desenvolvidos no
campo das geografias feministas e das
sexualidades. Sua reflexão aparece
vinculada as geografias feministas desde a
tese de mestrado sobre espaço e violência
contra mulheres em 1985 e,
posteriormente, na tese de doutorado
envolvendo espaços públicos e corpos
grávidas em 1997. Os estudos voltados a
compreensão da relação entre espaços e
corpos se seguiram com adoção de uma
abordagem das sexualidades e vinculada a
teoria Queer. De que forma os principais
debates políticos/acadêmicos das
geografias feministas e das sexualidades
estão ligados com sua trajetória intelectual
na geografia humana?

Robyn Longhurst: Para mim, geografia humana, e isso desde que eu era uma 
estudante do Mestrado em meados da década de 1980, nunca foi sobre humanos per se, mas sim sobre pessoas que eram homens, mulheres, trans, héteros, gays, lésbicas, bissexuais, etc. Lembro-me que quando li nos anos 80 'A critique of Sex/Gender Distinction' [Uma crítica da distinção de sexo/gênero] da Moira Gatens (1983) no qual ela argumenta que os corpos não são neutros, mas sim que "há no mínimo dois tipos de corpo, o corpo masculino e o corpo feminino [...] O sujeito é sempre um sujeito sexuado", e isso ressoou bastante em mim. Diversas vezes eu já tinha refletido como parecia impossível separar sexo e gênero e como sexo e gênero muitas vezes não coincidem, por exemplo, homens nem sempre são másculos nem mulheres são sempre femininas. $\mathrm{O}$ ensaio da Gaten juntamente com outras teóricas feministas como Elizabeth Grosz, Vicki Kirby, Iris Marion Young e Elspeth Probyn - deu-me inspiração para pensar de um modo diferente sobre geografia, espaço e lugar. As ideias delas ajudaram-me a compreender questões como violência contra a mulher e corpos grávidos, que você menciona em sua pergunta, e a explorá-las dentro de um enfoque da geografia. Creio que na época a minha orientadora pensou que violência sexual, e alguns anos depois, gravidez, não eram temas adequados para a pesquisa em geografia, mas eu estava determinada. $\mathrm{Na}$ minha concepção, violência contra as mulheres, bem como gravidez, eram temas tão relevantes, se não mais, que qualquer outro tema que pudesse escolher. Eles também diziam de minhas experiências pessoais. Eu queria pesquisar algo que tivesse conexão com minha vida.

R.R.: Em 2011, no I Seminário Latinoamericano de Geografia e Gênero ocorrido no Rio de Janeiro, no Brasil, você realizou uma conferência sobre a relação entre espaço e as experiências de mães solteiras estudantes em Aotearoa (Nova Zelândia), utilizando o conceito de espaço paradoxal de Gillian Rose (1993). Este conceito tem também sido bastante utilizado atualmente pela geografia feminista no Brasil. Na sua opinião, o conceito de espaço paradoxal se mantém interessante à compreensão da relação entre espaço e gênero e sexualidades na contemporaneidade?

R.L.: Penso que a Gillian Rose fez uma contribuição enorme com seu livro publicado em 1993 Feminism and Geography [Feminismo e Geografia]. Ela argumenta fortemente, como nenhum outro geógrafo feminista havia feito antes, sobre a necessidade de desestabilizar dualismos como $\mathrm{Eu}$ e o Outro. Ela também encorajou geógrafos feministas a usarem de diferentes estratégias para fazer a crítica do machismo da geografia. Desde sua publicação esse livro inspirou muitas pessoas, eu inclusive, a adotarem a ideia que o espaço é paradoxal, ou ambíguo, ou constituído por uma espécie de 'bricolagem' ou de qualquer outra maneira que se use para ressaltar a natureza complexa, contraditória e justaposta do espaço. Penso que, resumindo, a resposta para sua questão seria "sim". O conceito de espaço paradoxal ainda é útil para entender a relação entre espaço, gênero e sexualidades. O pensamento dualístico não deixou de existir. E ainda precisamos criticar distinções frequentemente feitas entre cultura/natureza, público/privado, produção/reprodução,

trabalho/casa, ocidental/oriental e homem/mulher, por exemplo. A geografia como disciplina ainda é machista. Gillian Rose argumenta, utilizando a noção de uma política do espaço paradoxal, que o feminismo necessita ocupar tanto o centro quanto as margens. Precisa ter mobilidade, ser contraditório e múltiplo, para que possa ameaçar a estrutura dualística que há bastante tempo domina a imaginação geográfica. Eu concordo com ela. Logo, sim, 
penso que o conceito de espaço paradoxal ainda é relevante e é bom saber que geógrafos feministas no Brasil façam uso efetivo desse conceito.

R.R.: Você escreveu individualmente ou em parceria com outros geógrafos e geógrafas, textos direcionados a compreensão das experiências de homens, de lugares e identidades masculinas e das masculinidades e sua relação com a geografia (LONGHURST, 2000; MORIN, LONGHURST e JOHNSTON, 2001; BERG e LONGHURST, 2003;). Os estudos sobre masculinidades emergiram no decorrer da década de 1990. Neste contexto, o feminismo absorvia com mais vigor as teorias pós-estruturalistas. Contudo, os estudos sobre masculinidades na geografia se tornaram pouco presentes nas conferências e seminários das geografias feministas e das sexualidades contemporâneos. Na sua opinião, quais contribuições podem resultar do desenvolvimento de pesquisas sobre homens, identidades masculinas e masculinidades?

R. L.: Penso que é muito importante que os geógrafos que se interessam em sexo e gênero não foquem somente mulheres, feminilidades e identidades femininas, mas, também, foquem homens, masculinidades e identidades masculinas e a relação entre eles. No começo dos anos 80 o foco estava, compreensivelmente, nas mulheres e suas vivências porque as mulheres haviam sido excluídas, e era uma questão vital "pôr as histórias das mulheres em pauta". Entretanto, nos últimos anos, tornou-se evidente que devemos também pensar sobre os homens, tanto em relação às mulheres quanto por si próprios. Precisamos estudar aqueles que detêm identidades normativas ou hegemônicas e não somente aqueles que foram Outrificados ou marginalizados. Então, por exemplo, em estudos da sexualidade é cada vez mais comum problematizarem e contestarem sexualidades - héteros normativas. Em estudos sobre raça e etnicidade as pessoas estão refletindo sobre "brancura". Nos estudos feministas houve uma mudança de foco da reflexão, deixando de focalizar somente as mulheres para considerar também os homens. Para desestabilizar relações de poder patriarcais faz-se necessário que examinemos não somente a feminilidade, mas, também, a masculinidade e a relação entre esses dois constructos.

R.R.: O livro Bodies: Exploring Fluid Boundaries (2001) revela um longo e interessante processo de pesquisa social e reflexões sobre as dimensões material, subjetiva e fluída do corpo, e respectivamente, como ele é potencialmente subversivo, abjeto ou marginalizado quando feminilizado, afeminado ou dissonante em diferentes espaços. Em sua reflexão e de Johnston (2008; 2010), sugerem que o corpo é um instrumento de pesquisa e que as possibilidades de operacionalizar esta faceta metodológica revelam uma evolução da abordagem sobre o corpo na geografia. Gostaríamos que compartilhasse conosco algumas imaginações geográficas que podem surgir desta evolução.

R.L.: Sempre tive como foco de meu interesse o corpo e toda sua materialidade escatológica. Como você notou, eu foco isso no livro Bodies, e Lynda e eu retornamos ao tema no nosso livro Space, Place and Sex e em nosso artigo 'Using the body as an instrument of research' [Usando o corpo como um instrumento de pesquisa], quando utilizamos como metodologia de pesquisa o cozinhar e o comer com mulheres migrantes 
em Hamilton, Nova Zelândia. Sua pergunta, sobre que imaginação geográfica pode emergir desse trabalho tendo corpos como matéria e como potencialmente abjetos, é interessante e é algo que Lynda e eu estamos pensando ultimamente, já que estamos preparando um artigo que reflita sobre como "o corpo" foi abordado em 21 anos de publicação, isso é desde sua fundação em 1994, do Gender, Place and Culture. Nós argumentamos que no passado a simples menção dos corpos, especialmente de sua materialidade escatológica, causava escrúpulos, para dizer o mínimo, em muitos geógrafos (LONGHURST \& JOHNSTON a ser publicado). Hoje em dia é frequente os corpos serem temas de discussão, e isso em diversos enquadre, incluindo teoria nãorepresentacional, geografias performativas e geografias da emoção e afeto, então as coisas mudaram. Agora os corpos estão na pauta de muitos geógrafos sociais, psicanalíticos, antiracismo, queer e feministas. Então penso que, pode-se dizer finalmente que eles [os corpos] são parte de uma imaginação geográfica específica, mas ainda há muitos lugares, e algumas sub-disciplinas, que limitam essa discussão. Por exemplo, pode ser aceitável escrever sobre emoção e afeto, performatividade, e o inconsciente, mas não é [aceitável] escrever sobre sangue menstrual, incontinência ou outros fluídos corporais que fazem parte de nosso cotidiano. De modo que corpos carnais "reais", tanto do pesquisador quanto do pesquisado, ainda são considerados muito mundanos, muito materiais, muito feminilizados - muito Outro - para a geografia.

R.R.: O livro Gender place and sex: Geographies of sexualities publicado com Lynda Johnston em 2010, representa um importante passo da geografia humana no combate a homofobia. Como a perspectiva geográfica das sexualidades, corpo, espaço e lugar presente no livro tem repercutido nas ciências sociais e nos movimentos feministas e LGBT?

R. L.: Sempre é difícil saber o impacto que nosso trabalho pode ou não causar em diferentes indivíduos e comunidades. Lynda e eu tentamos escrever Space, Place and Sex de modo que fosse acessível para um público amplo. Tínhamos a esperança que ele fosse lido também por pessoas de fora da academia. Não temos certeza em que grau isso ocorreu, mas não muito tempo depois da publicação do livro nós fomos convidadas para participar de um programa de TV matutino. Isso foi um pouco assustador - uma entrevista ao vivo antes do café-da-manhã! Entretanto, issodeunos a oportunidade de falarmos com uma vasta e diversificada audiência sobre o papel que lugar exerce na formação de nossa sexualidade, algo que muitas pessoas não costumam refletir sobre. Foi bastante positiva a reação à nossa entrevista.

R.R.: Muitas pesquisadoras(es) das geografias feministas e das sexualidades deparam-se com a ausência de trabalhos teóricos e experiências de pesquisas anteriores para interlocução. Alguns dos estudos que você desenvolveu foram pioneiros e raros na produção geográfica. Entre eles podemos apontar a relação entre espaço e corpos de mulheres grávidas (2005), obesidade (2005), erotismo rural (2010), a casa ou o cozinhar (2013). Quais são os principais desafios e ensinamentos que este modo de produzir uma ciência geográfica tão pouco explorada podem proporcionar?

R. L.: Dentre os muitos temas por mim abordados no curso dos anos, houveram vários que eram considerados como indignos de atenção acadêmica, isso é, temas que não eram considerados como "apropriados" ou "sérios". Isso significa que tive que encarar

Rodrigo Rossi 
alguns desafios, como comentários maldosos feitos pelas minhas costas. Outras vezes fui confrontada com questionamentos diretos do tipo "e o quê que isso tem a ver com geografia?" Entretanto, foi fato de ter abordado áreas subjetivas, áreas ignoradas durante muito tempo, que possibilitou a criação de novos conhecimentos e de novos espaços de crítica. Como argumento no Bodies, a micro política que impregna os corpos é tão importante quanto à macro política que impregna os Estados nacionais. $\mathrm{O}$ que é considerado como conhecimento legítimo dentro da geografia é complexo e merecedor de exame. Importa qual conhecimento está sendo produzido. Mas também importa quem está produzindo e onde ele é produzido. Essas são questões que quis levantar quando escolhi temas como gravidez, obesidade e cozinhar em casa.

R.R.: Alguns de seus estudos recentes envolvem a problematização do ambiente virtual e o ciberespaço. Quais são as potencialidades das tecnologias de informação e comunicação, tais como youtube (2009) e skype (2013), como fontes de pesquisa e reflexão nas geografias feministas e das sexualidades?

R. L.: Sim, nos últimos tempos tenho trabalhado com as temáticas de sexo, gênero, corpos e tecnologias comunicacionais e informacionais. Parece-me que cada vez mais vivemos simultaneamente em espaços off-line e on-line que estão cada vez mais enredados e, sendo assim, é importante entender as implicações disso. Penso que há potencial para que os geógrafos interessados em mídias e comunicação e os geógrafos interessados em sexo e gênero trabalhem cada vez mais próximos. Eu estou escrevendo atualmente um artigo baseado na vivência de 35 mães que vivem em Hamilton, Nova Zelândia, e usam as tecnologias comunicacionais para conectarem-se com seus filhos. Estou explorando a capacidade de diversas tecnologias, tanto isoladamente ou em conjunto, de provocar diversas emoções e afetos. $\mathrm{O}$ artigo conclui que as tecnologias de comunicação digital não são coisas frias, racionais, apartadas de experiências viscerais, mas sim que se entrecruzam com a emoção e o afeto. Também estou escrevendo um livro sobre o Skype. Estou fascinada pelo modo como as chamadas de áudio e vídeo em tempo real podem prover indicações visuais como: expressões faciais, gestual, tom de voz e pausas, bem como a local de onde se fala, podem criar a sensação de "presença". O livro foca como o Skype está transformando relações sociais, sexuais e de gênero.

R.R.: Qual a importância das experiências na Comissão de Gênero da União Geográfica internacional para a sua trajetória intelectual, como feminista e adepta da Teoria Queer? Pode estabelecer uma breve apreciação sobre o estágio de desenvolvimento e difusão das geografias feministas e das sexualidades no mundo?

R.L.: Eu amei estar envolvida nessa década que passou com a Comissão de Gênero e Geografia da UGI. É um grupo de aproximadamente 600 geógrafos de aproximadamente 60 países. Como você bem sabe, pois o Brasil esteve, e continua, envolvido com a Comissão, tendo inclusive sediado um importante encontro no Rio de Janeiro em 2011. Todos os anos nós organizamos eventos e nos conectamos através de um boletim informativo enviado por e-mail pela professora Janice Monk. É excelente sua pergunta sobre o estágio de desenvolvimento e disseminação pelo mundo das geografias feministas e das sexualidades e eu farei o melhor possível para respondê-la. O maior número de assinantes da lista de Gênero e Geografia está nos EUA, Reino 
Unido e Índia onde a participação cresceu rapidamente nos últimos anos. A Comissão também tem membros na Espanha, Canadá, Austrália, Itália, Suíça e em meu próprio país, a Nova Zelândia. Também temos alguns assinantes, mas não muitos, na Europa ocidental, especialmente Bélgica, Alemanha, Áustria e França. Porém, infelizmente, no leste e sudoeste asiático temos poucos assinantes que não sejam do Japão, que sediou um encontro em 2013. A participação também é limitada nos países africanos e na Europa do Leste, mesmo tendo acontecido um encontro em 2009 na Hungria e Romênia que gerou algum interesse. Não temos muitos assinantes do Oriente Médio, ainda que hajam alguns de Israel. Na América Latina a adesão está limitada a Argentina, México e Brasil. $\mathrm{Na}$ verdade, nos últimos anos tivemos um crescimento real no número de assinantes do Brasil, o que é fantástico. Creio que isso não seja surpreendente se levarmos em conta o surgimento da Revista Latino Americana de Geografia e Gênero e a publicação de um certo número de coletâneas editadas sobre os temas de gênero e sexualidade. É bom ver isso acontecer. A edição especial da Belgio editada pela Maria Dolors Garcia Ramon e Janice Monk (2007) sobre "Feminist Geographies around the World" [Geografias Feministas ao redor do Mundo] é uma fonte útil para quem quiser saber mais sobre a disseminação da geografia feminista ao redor do globo. Bem como o artigo anterior (1994) da Janice Monk. De todo modo, parece que os geógrafos progrediram bastante nas áreas de gênero e sexualidade, mas ainda há um longo caminho a ser percorrido!

\section{Referências}

BERG, Lawrence; LONGHURST, Robyn. Placing Masculinities and Geographies, Gender, Place and Culture: A Journal of Feminist Geography, v. 10, n. 4, p. 351-360, 2003.

GARCIA RAMON, Maria Dolores; MONK, Janice. Feminist Geographies around the World (guest edited special issue of Belgeo) 2007.

GATENS, Moira. A Critique of the Sex/Gender Distinction. In: ALLEN, Judith; PATTON, Paul (Eds.) Beyond Marxism: Interventions after Marx. Leichhardt: Intervention Publication, 1983, p. 143 - 160.

JOHNSTON, Lynda.; LONGHURST, Robyn. Space, place and sex: Geographies of sexualities. Lanham - Maryland: Rowman \& Littlefield Publishers Inc, 2010.

JOHNSTON, Lynda; LONGHURST, Robyn. Trans(itional) geographies: bodies, binaries, places and space (translated into Portuguese), In:SILVA, Joseli Maria; ORNAT, Marcio Jose; CHIMIN JUNIOR, Alides Baptista (Eds.). Geografias Malditas: corpos, sexualidades e espaço. Ponta Grossa: Todapalavra, 2013a, p. 339 - 355p.

JOHNSTON, Lynda; LONGHURST, Robyn. Mixed feelings: migrant women's experiences of food, eating and home in Hamilton, Aotearoa New Zealand. Hagar: Studies in Culture, Polities and Identities, v. 11, n. 1, p. $20-40,2013$ b.

LONGHURST, Robyn: Feminist perspectives on home. In: SMITH, Susan (Ed.). International Encyclopaedia of Housing and Home. Elsevier: Oxford 2012, p. $158-$ 162.

LONGHURST, Robyn; HODGETTS, Darrin; 
STOLTE, Ottilie. Mães solteiras que estudam em Aotearoa, Nova Zelândia: Uma política de espaço paradoxal. In: SILVA, Joseli Maria; SILVA, Augusto Cesar Pinheiro da (Eds.) Espaço, gênero e poder: conectando fronteiras. Ponta Grossa: Todapalavra, 2011, p.171- 184.

LONGHURST, Robyn. Bodies: Exploring Fluid Boundaries, London: Routledge, 2001.

LONGHURST, Robyn. Breaking corporeal boundaries: pregnant bodies in public places. In: HOLLIDAY, Ruth; HASSARD, John (Eds.) Contested Bodies. London: Routledge, 2001, p. $81-94$.

LONGHURST, Robyn. Stretching mothering: gender, space and information communication technologies. Hagar: Studies in Culture, Polities and Identities, v. 11, $\mathrm{n}$. 1, p. 121-138, 2013.

LONGHURST, Robyn. Using Skype to mother: bodies, emotions, visuality and screens, Environment and Planning D: Society and Space, v. 31, n. 4, p. $664-679$, 2013.

LONGHURST, Robyn. YouTube: a new space for birth?. Feminist Review, v. 93, p 46-63, 2009.

LONGHURST, Robyn; HO, Elsie; JOHNSTON, Lynda. Using the body as an instrument of research: kimch'i and pavlova. Area, v. 40, n. 2, p. 208-217, 2008.

LONGHURST, Robyn. '(Ad)dressing Pregnant Bodies: Fashion, Clothing and Subjectivities'. Gender, Place and Culture: A Journal of Feminist Geography, v. 12, n. 4, p. 433-446, 2005.

LONGHURST, Robyn. Fat Bodies: Developing geographical research agendas. Progress in Human Geography, v. 29, n. 3, p. 247-259, 2005.

LONGHURST, Robyn. Geography and gender: masculinities, male identity and men. Progress in Human Geography, v. 24, n. 3, p. 439-444, 2000.

LONGHURST, Robyn; JOHNSTON, Lynda. Bodies, Gender, Place and Culture: 21 years on, Gender, Place and Culture, forthcoming.

MONK, Janice. Place matters: Comparative International Perspectives on Feminist Geography. The Professional Geographer, v. 46, n. 3, p. 277 - 288, 1994.

MORIN, Karin; LONGHURST, Robyn;JOHNSTON, Lynda. (Troubling) spaces of mountains and men: New Zealand's Mount Cook and the Hermitage Lodge. Social and Cultural Geography, v. 2, n. 2, p. 117-139, 2001.

ROSE, Gillian. Feminism \& Geography. The limits of Geographical Knowledge. Cambridge: Polity Press, 1993. 